\title{
Trinta anos de construção identitária Sem Terra no Espírito Santo: explorando um Projeto Político- Pedagógico de vanguarda contra o neoliberalismo
}

\author{
Michalis Kontopodis
}

\section{Resumo}

O neoliberalismo global é marcado pelo desejo de ser bem-sucedido, consumir produtos e serviços, ou até mesmo pessoas ou bens imateriais em um não-lugar, oferecendo uma experiência de um não-tempo. Dessa forma, algumas perguntas podem ser feitas, dentre elas, quais seriam as alternativas para o neoliberalismo e qual seria o papel da pedagogia nesse contexto? Tomando como referência o Movimento dos Trabalhadores Sem Terra (MST), o presente texto analisa como as políticas de memória e de identidade estão envolvidas em imaginar futuros que não seguem linearmente do passado. O material empírico vem de uma pesquisa etnográfica realizada nos últimos cinco anos (2007-2012) no Espírito Santo. O artigo também analisa os componentes centrais da Pedagogia Sem Terra, a construção identitária na escola, a solidariedade e o partilhar de memórias sobre o passado local, como alternativas radicais ao neoliberalismo global. Mas como pode o projeto políticopedagógico do MST ser levado adiante para incluir todos os "Outros" que sofrem devido às relaçóes de poder no Brasil e ao redor do globo?

Palavras-chave: Movimento dos Trabalhadores Sem Terra. Pedagogia Crítica. Globalização.

\footnotetext{
* Doutor pela Faculdade de Educação e Psicologia, Universidade Livre de Berlim, Alemanha. Professor Assistente na Faculdade de Psicologia e Educação, Universidade Livre de Amsterdá, Holanda e na Faculdade da Educação, Universidade Roehampton, Inglaterra. Web: http:// mkontopodis.wordpress.com
} 


\title{
Prefácio: olhando para o futuro
}

\begin{abstract}
Quando uma pessoa decide morar em Beijing, trabalhar em Beijing, ou fazer um tour pela cidade, sua decisáo na verdade significa aceitar e assumir um papel em um drama, com a esperança de tornar-se parte do futuro e de suas promessas de uma excitaçáo constante, trazida por uma vida urbana mais ativa que em qualquer outro lugar. Essa decisão significa, também, mover-se em um lugar onde cada visitante conta apenas com o futuro, nunca com o passado. Para qualquer pessoa, China Central Place é um símbolo que representa a cidade moderna de Beijing, a capital chinesa. (Inscrição de um monumento em Beijing, China, escrito originalmente em inglês e mandarim).
\end{abstract}

Fiquei muito surpreso ao ver uma inscrição em um monumento moderno construído no centro de uma das mais modernas áreas de Beijing, China, no verão de 2011. Embora o monumento diga que ele se refere apenas ao futuro, o texto está escrito em letras de ouro ou mármore, imitando, dessa forma, uma técnica tradicional (não chinesa, aliás). Se o mesmo texto tivesse sido escrito com técnicas luminosas modernas, entáo representaria melhor o que é "o futuro", mas pareceria muito mais com um comercial. Poderia, então, ser ainda considerado um monumento? Geralmente os monumentos materializam memórias passadas. Todavia, este contradiz a velha noção monumentum, do latim monere, que significa permanecer. É um monumento que apaga o passado e testemunha apenas o futuro. Ele evoca um espaço público no qual o visitante tem apenas o futuro, nunca o passado.

O leitor poderia entender aqui uma oposição destacada: esse novo Complexo Central de Beijing tem apenas um futuro, ao contrário da Praça Tiananmen, que tem sido a praça central por longa data. A Praça Tiananmen não pode migrar para o futuro, porque está fixada às memórias do passado. Ela é o lugar onde o Mausoléu Mao Zedong, ainda aberto aos visitantes, materializa a contradição entre a economia de livre mercado e o regime anterior; é também o lugar onde, bem conservadas antigas construçóes imperiais, materializam a longa e contraditória história da entidade geográfica que é atualmente chamada "China". O que é ainda mais importante, visto da minha perspectiva, é que 
entre esses memoriais todos os traços e evidências dos protestos e assassinatos de estudantes ocorridos em 1989 foram cuidadosamente apagados, enquanto as memórias dos tanques de guerra se aproximando ainda estão lá (AGAMBEN, 1993).

Mas por que razão alguém se importaria com esta história e com as políticas nela envolvidas? O discurso do monumento ainda continua:

Visite você mesmo o Complexo do China Central Place e ficará assombrado pela perfeita relação entre os cenários, a arquitetura e os espaços abertos que são divididos pelos prédios. Cada elemento ecoa outros. Até mesmo uma simples fábrica é desenhada para ser funcional na vida atual. O China Central Place é um projeto complexo combinando designs perfeitos e detalhados, que não podem ser refletidos em nenhum elemento de forma individual. O China Central Place está oferecendo às pessoas que aqui trabalham, habitam ou visitam uma incomparável forma de apreciação, diversão e multiplicidade de serviços. (Inscrição no monumento, China Central Place, em Beijing, escrito originalmente em inglês e mandarim).

"O China Central Place está oferecendo às pessoas que aqui trabalham, habitam ou visitam uma incomparável forma de apreciação, diversão e multiplicidade de serviços" - e o que mais alguém poderia desejar para si? Esperava-se que eu me sentisse tocado pelo acesso à multiplicidade de serviços, entretanto, isso não me parece muito apelativo. $\mathrm{O}$ que as pessoas podem fazer em um local sem história? Pareceu-me que o único futuro apresentado nos espaços tão perfeitamente desenhados era a promessa do consumo: "promessas de uma excitação constante, trazida por uma vida urbana mais ativa que em qualquer outro lugar”. Esta excitação é privada, uma vez que não pode existir nenhum senso de comunidade sem memórias passadas.

E não somente o passado foi apagado, mas também o presente: em vez de "olhar para" os múltiplos e heterogêneos passados, presentes e futuros das pessoas que habitam Beijing, esta praça é perfeitamente "desenhada" como um não-lugar, oferecendo uma experiência de um não-tempo. Se os nomes dos lugares fossem removidos, as linhas acima citadas (escritas em inglês no original) poderiam ter sido escritas em praças centrais semelhantes "perfeitamente projetadas" e 
situadas em Los Angeles, Berlin, São Paulo ou Moscou. Isso, na verdade é o neoliberalismo global - uma forma de olhar para o futuro sem ver nada além ${ }^{1}$.

\section{Neoliberalismo}

Passaram-se mais de 15 anos desde que Arjun Appadurai (1996), no seu arrebatador livro Modernity at large: cultural dimensions of globalization, descreveu como até mesmo os habitantes de remotas vilas nas montanhas na Índia sonham viver em Nova Iorque ou Hollywood. Ele argumentou que as imagens circulam pelo mundo através da mídia mais facilmente na atualidade, e mesmo que a pessoa nunca tenha tido a oportunidade de ver um comercial ou filme, já ouviu narrativas de migrantes ou parentes sobre a vida nesses lugares. Appadurai (1996) descreveu como pessoas, informaçôes, imagens e capital passam de um lugar para outro de forma extraordinária, tornando o mundo um todo interconectado.

De fato, índios Guaranis, da regiáo do Espírito Santo, ou Tucanos, da regiáo do Amazonas, por exemplo, mesmo habitando em casas feitas de barro e madeira bruta, sem nenhuma tecnologia moderna, puxam eletricidade de um poste central só para poder ter as suas TVs e antenas conectadas, por pelo menos uma ou duas horas por dia. O mesmo é o caso de habitantes de outras áreas rurais - até mesmo os Trabalhadores Rurais Sem Terra, a cujo movimento radical farei referência.

Poder-se-ia dizer que o mundo interconectado descrito por Appadurai (1996) - ou o Império, para usar outro termo proposto por Michael Hardt e Antonio Negri (2001) - é marcado principalmente por duas tendências: (a) o desejo de ser bem-sucedido e consumir - não aproveitar, compartilhar ou criar, mas consumir produtos, serviços, até mesmo pessoas ou bens imateriais; e (b) a inabilidade de ser bem-sucedido e acessar, apropriar-se e consumir todos esses produtos, serviços e bens (BAUMAN, 2007). Especialmente quando falam sobre gente jovem, fica claro que quanto mais deslumbrantes se tornam os comerciais e as imagens desses produtos, mais excluídos ou marginalizados se sentem as pessoas que não conseguem acessá-los ou possuí-los nas diversas periferias do nosso mundo. Essa crise, que é diretamente associada à economia capitalista, tem recentemente afetado seriamente até mesmo regiōes periféricas dos Estados Unidos da América, da União Europeia e outras economias avançadas. 
As políticas de identidade globais assumem, geralmente, duas formas diferentes neste cenário: (a) rompimento de qualquer conexão com o passado e contínua reinvenção de si, que deve então ser flexibilizado para caber perfeitamente dentro do mercado de trabalho e consumo; (b) nostalgia do passado, que está frequentemente conectada ao nacionalismo, ao fanatismo religioso e à exclusão da alteridade. Essas tendências mostram uma profunda crise ético-política global: individualismo sobre altruísmo, competição sobre solidariedade, hostilidade sobre paz e colaboraçáo, homogeneidade em detrimento da heterogeneidade (KONTOPODIS, 2012) ${ }^{2}$. Aqui a questão se apresenta por si mesma: quais seriam as alternativas para essas políticas de identidade e qual o papel da pedagogia nesse contexto?

Para responder a esse questionamento, irei explorar como as políticas de memória e de identidade estão envolvidas em imaginar e aspirar futuros que não seguem linearmente do passado, tomando como referência a política identitária do Movimento dos Trabalhadores Sem Terra (MST). Ainda que tenha sido desde o começo considerado como um movimento unificado e centralizado, percebem-se grandes diferenças entre os diversos assentamentos e acampamentos. Cada um deles tem sua própria história local, composiçáo populacional, características geográficas e diferenças ideológicas. A presente pesquisa foi realizada em diferentes regióes brasileiras, mas este texto se restringe ao Movimento dos Trabalhadores Rurais Sem Terra do Espírito Santo.

O material empírico vem de uma pesquisa etnográfica realizada nos últimos cinco anos (2007-2012), em colaboração com pesquisadores brasileiros que investigam sobre o MST, principalmente, Erineu Foerste e Gerda M. Schütz-Foerste, da Universidade Federal do Espírito Santo (UFES), Johannes Doll, da Universidade Federal do Rio Grande do Sul (UFRGS), e Isabela Camini, pesquisadora sênior na unidade de pesquisa do MST (FOERSTE; FOERSTE-SCHÜTZ; DUARTE-SCHNEIDER, 2008).

Nesta pesquisa foi realizada uma análise qualitativa e interpretativa, sendo os materiais que serão apresentados representativos do conjunto mais amplo de dados coletados. Já existe muita propaganda de diferentes grupos de interesse a favor do MST, assim como outros tantos contrários. Esta é uma polaridade que conscientemente tento evitar, embora me posicione como solidário aos movimentos sociais em geral e, em particular, com o Movimento dos Trabalhadores Rurais Sem Terra. 


\title{
O projeto "Nossa identidade"
}

\author{
Professora Raquel: Bem, como eu falei com vocês: Quem \\ aqui que já conhece o que é um acampamento? \\ Estudantes: - Eu. - Eu. - Eu [...]. \\ Professora Raquel: Já viram as barraquinhas? "Márcia" \\ você conhece um acampamento? \\ Estudante 1: Eu não. \\ Professora Raquel: Tá. Acampamento. Quem já foi lá visitar as \\ pessoas que estão lutando pela "luta da" terra? [...] pela conquista \\ da terra [...] ainda tão morando debaixo da lona? "Aî"ó: são \\ poucos os que já viram um acampamento [...]. \\ (Transcrito da gravação de vídeo realizada em uma escola \\ de Trabalhadores do MST).
}

A cena apresentada acima vem de uma atividade de sala de aula que observei durante a etnografia em um acampamento no Espírito Santo em ano 2009. O acesso foi favorecido pela professora $\mathrm{Raquel}^{3}$, coordenadora da atividade acima $^{4}$. Fui apresentado à ela por professores universitários colaboradores, que já haviam realizado pesquisas por lá e tinham sido muito bem acolhidos. Nós estávamos em uma pequena escola. As escolas primárias nos assentamentos dos MST têm, geralmente, uma ou duas classes multisseriadas com crianças de 5 a 13 anos, como é o caso dessa a qual me refiro. Para a atividade apresentada, todas as crianças das duas turmas (mais velhos e mais jovens) ficaram juntas. A professora Raquel (T1) começa com uma questão retórica que objetiva provocar a curiosidade das crianças e envolvê-las na lição que segue. Ela se refere a um acampamento que existe não táo distante daquele local onde as crianças vivem, para depois falar sobre os primeiros acampamentos e a história do Movimento dos Trabalhadores Rurais Sem Terra: "Então, nós vamos mostrar hoje pra vocês algumas fotos, de alguns acampamentos, tá? Acampamentos que nossas famílias passaram [...]" (Professora Raquel, transcrito da gravação de vídeo realizada em uma escola de Trabalhadores do MST).

Para esta atividade particular, a professora Raquel não usa livros ou materiais impressos. Em vez disso, ela apresenta suas próprias fotos de família e fala do MST como um todo ao se referir à parte que é relevante para as crianças: a história do acampamento no qual eles vivem e as histórias de suas famílias, atraindo-os com as fotos e as narrativas. Muitas fotografias retratam a família da 
professora Raquel e outras pessoas do acampamento (agora assentamento) em diferentes fases antes de passarem a viver no lugar onde então estavam. Várias fotos, entretanto, não aparecem pessoas, mas materialidades: a barraca na qual eles viviam no acampamento, a primeira parede que construíram do que mais tarde viria a ser a sua casa, a escola e assim por diante. Outras imagens eram dos parentes ou amigos que participaram das principais manifestaçóes do MST.

Professora Clarice: $O$ projeto que nós vamos comę̧ar a trabalhar com vocês é o projeto "Nossa identidade". Então, quando vocês olham um acampamento desse, por mais que vocês não tenham passado por acampamento [...] os pais de vocês "passaram", os "avós" de vocês passaram [...] Então essa é que é nossa identidade. E mesmo que vocês ou os pais de vocês não tenham passado por um acampamento, e vocês tão aqui hoje num assentamento, que faz "parte" do Movimento Sem Terra, então "a par", automaticamente, vocês já são, "já faz" da identidade de vocês, "já"é do Movimento Sem Terra.

Tomando a fala de sua colega, a professora Raquel explica para as crianças por que a atividade é importante. Manter as memórias caminha junto com construir a identidade, o que implica em um sentimento de pertença e um senso de responsabilidade, não somente para si, mas para a comunidade como um todo à qual pertencem as crianças (KONTOPODIS; MATERA, 2010). Conforme a professora explica, mesmo que as crianças não tenham vivenciado as lutas de seus pais e dos membros de sua comunidade, o passado pertence também a elas, de forma a moldar sua identidade. Quase automaticamente, elas são os filhos dos Trabalhadores Sem Terra, isto é, Crianças Sem Terra - ou Sem Terrinha, como eles dizem. A professora evoca um passado coletivo, compartilhado pelas crianças - não no sentido de experiência pessoal, mas de memória coletiva. O discurso sobre mártires e solidariedade é de responsabilidade e identidade coletivas. Raramente se encontra um discurso semelhante em outras escolas brasileiras, que estão cada vez mais sendo orientadas ao sucesso individual.

A pedagogia específica nesse trabalho político é chamada Pedagogia da Terra. Aqui a educação náo consiste somente em ser essencial aos Trabalhadores Sem Terra a fim de que eles desenvolvam novas tecnologias ecológicas de plantio, estratégias para negociar seus produtos ou ter seus próprios doutores nos assentamentos, mas existe também a ideia de educar as crianças de forma 
que elas, coletivamente, possam participar na transformação do mundo no qual vivem. Emerge, então, um novo tipo de escola que objetiva transformar a sociedade. Por outro lado, esse futuro poderia ser imaginado apenas pela memória da história local de exploração e luta. Isso não é educação, mas formação, como dizem os Trabalhadores Sem Terra.

Nesse mesmo contexto, quando alguém visita o assentamento, encontra uma plenitude de evidências da sua história na decoração interior, estampada em camisetas, representada nas fotos dos massacres, nos poemas escritos ou em CDs com músicas dos Sem Terra. O movimento tem uma significativa produção simbólica e discursiva, que envolve o imaginário e manifesta importantes qualidades estéticas. Valorizam fortemente as artes e expressam a si mesmos na música, poesia e teatro. Os Sem Terra consideram a arte como portadora de elementos místicos capaz de unir os seus membros, constituída da Pedagogia da Terra e construtora de parte da identidade, como escreve Roseli Caldart (2004), uma das principais figuras intelectuais do Movimento.

Um livro editado recentemente por Claudia Mitchell, Teresa StrongWilson, Kathleen Pithouse e Susann Allnutt (2011) investiga a relevância social e pedagógica de um trabalho embasado na memória - um processo que permite aos estudantes verem o futuro como algo que pertence a eles e que podem influenciar de maneira melhor. Niamh Stephenson e Dimitris Papadopoulos (2006) também argumentam que compartilhar experiências de opressão criam as condições para uma sociabilidade no fazer, isto é, para as pessoas agirem juntas sem necessariamente uma tornar-se igual à outra. Fotografias pessoais, narrativas e trabalhos de arte sobre as lutas passadas e os sonhos comuns fazem a mediação da comunicação entre professores, membros adultos da comunidade e os Sem Terrinha, habilitando-os, portanto, a escapar das políticas de identidade dominantes e das relaçóes de poder neoliberais descritas na primeira parte do artigo.

\section{Solidariedade}

O que é exatamente ser ou tornar-se Sem Terra? Estimados 1,5 milhóes de marginalizados urbanos ou rurais, que tem construído o Movimento dos Trabalhadores Sem Terra nos últimos 30 anos ocuparam terras que pretendiam cultivar coletivamente de modo ecológico e democrático 5 . As crianças Sem Terra, nesse contexto, deveriam ocupar mais terras, uma vez que o Movimento deverá ter 
sempre terra suficiente (as quais não seriam divididas entre membros das famílias que estão se expandindo). A questão principal do MST tem sido desde o seu início a Reforma Agrária brasileira - uma luta que continua até os dias de hoje. Ocupaçóes contínuas, deslocamentos, acampamentos, reassentamentos e uma série de demonstraçóes e confrontos violentos com a polícia marcaram a história do MST.

A apresentação das professoras foi detalhada e muito viva, captando profundamente o interesse das crianças. A Professora Raquel falou dela mesma e de outras pessoas que as crianças conheciam e que viviam no acampamento lutando contra a violência da polícia, as condiçóes de vida precária, as dificuldades práticas e políticas, e lentamente vão lidando para criar o assentamento onde agora vivem. Quando chegou a hora de perguntar, a estudante Ana, uma das crianças, levantou a mão e fez a primeira pergunta:

Estudante Ana: Ah tia, quando vocês estavam nas barracas, vocês passaram "fome"?

Professora Raquel: Ah, ela está perguntando se a gente, quando acampado, passou fome. Às vezes ficava muito difícil, a alimentação ficava pouquinho. A gente quase não tinha [alimentação]. Mas fome não passamos "não"! Que tinha "muita" solidariedade! Quando uma família não tinha, pegava uma lata de óleo, e a gente dividia o óleo na colher, dava duas, três colheres para cada familia, era a conta de colocar na panela [...] As crianças eram as que mais comiam no acampamento! Porque todo mundo levava "leite", "fruta". Às vezes faltava o básico, porque quem dá a "cesta básica" é o INCRA [Instituto Nacional de Colonização e Reforma Agrária], e às vezes atrasava e as familias ficavam com um pouco de dificuldade, mas a gente dividia uma(s) com as outras "tudo" o que a gente tinha [...].

A pergunta, entre tantas outras semelhantes que foram postas, é bem simples no sentido de estar relacionada aos detalhes práticos dos primeiros passos do movimento. Por outro lado, expressa a profunda afetividade que estudante Ana sente em relação à professora Raquel e às outras pessoas que batalharam pelo que agora ela pode usufruir. Percebe-se como a estudante compreendeu o discurso das professoras sendo concernente, co-experienciando o drama de seus predecessores.

A Professora Raquel repete a pergunta de forma dialógica e a toma enquanto oportunidade para explicar de forma viva e detalhada como a 
solidariedade tem sido a solução para muitos problemas que os Trabalhadores Sem Terra enfrentaram em outros momentos: "Quando uma família não tinha [...]". Também enfatiza que as crianças eram sempre tratadas de forma especial, recebendo a maior parte da comida do acampamento enquanto "a gente dividia uma(s) com as outras "tudo" o que a gente tinha". Os detalhes práticos preparam as crianças para moverem seu conhecimento concreto quotidiano para um discurso mais abstrato sobre solidariedade e identidade - que novamente não é apresentado com base em princípios éticos abstratos, mas através de categorias dramaticamente experienciadas.

As emoçôes assumem um papel importante, pois trazem pessoas diferentes para atuarem juntas, assim, transformando tanto a elas mesmas como as relaçôes sociais nas quais estáo envolvidas. As emoçóes estabelecem o "conatus" - no sentido atribuído por Espinoza (2007) - a força para lidar com a realidade ao atuar com outros e não sozinho (LIBERALI; FUGA, 2007). Ao participarem das atividades da sala de aula, as crianças puderam se perceber não como indivíduos isolados, mas como parte de uma história de criação de descontinuidade com o passado do Brasil Colonial - uma história que só começou recentemente e que continua a ser escrita. A historicidade da narrativa da professora Raquel é muito concreta e, ao mesmo tempo, abstrata: é a história dos pais ou vizinhos daquelas crianças e, ao mesmo tempo, a história do colonialismo e da luta pela Reforma Agrária. Abre-se, então, espaço náo apenas para as crianças se perceberem a partir de uma metaperspectiva, mas também para participarem diretamente e efetivamente na construção histórica.

\section{"Às vezes nós lembramos estes momentos com velhos companheiros e choramos"}

Está anoitecendo, faz calor e nós sentamos lá fora. Eu faço todas as perguntas possiveis sobre meu campo de pesquisa e João traz uma caixa cheia de fotografias que nunca foram ordenadas. Maria, sua esposa, e Fernanda, sua filha, também deixam a casa e vêm para o pátio e se sentam perto de mim. Eu pego algumas fotos e começo a olhá-las vagarosamente, uma após a outra. Maria me explica quem aparece em cada uma delas. A maioria das fotos retrata a familia ou outras pessoas do acampamento [agora assentamento] nos diferentes estágios passados por eles antes de começar a viver como Sem Terra no 
lugar onde estamos. Realmente entusiasmado e interessado eu faço perguntas constantemente. João está feliz com meu interesse, mas tenta encontrar duas fotos entre as muitas outras na caixa. "Sim - aqui estão elas!" ele diz com entusiasmo e mostra as fotos para mim. Conforme ele explica, uma foi feita recentemente: ela retrata a colina com todas as suas árvores e plantas, onde João e Maria trabalham agora. A outra foto retrata o mesmo local há 15 anos. Eu me impressionei. Pedrase terra cobrem a área e há apenas uma árvore. "Naquele tempo", explica João, "ninguém cultivava nada aqui. Não existia água e nem irrigação. Nós construimos o açude que você viu antes para conter a água da chuva, então plantamos as árvores e agora [...] Você vêe?" Ele está tão feliz por ter encontrado as fotos e por dividir suas memórias e experiências comigo. "Às vezes nós lembramos estes momentos com nossos velhos companheiros e choramos", ele me conta em frente das muitas fotografias sobre a mesa do jantar. E completa: "Agora não é tâo dificicl para os novos ocupantes de terras, eles jamais imaginariam como foi difícil no nosso tempo [...]"

Figura 1 - Campos dos Trabalhadores Rurais Sem Terra em torno de 1993

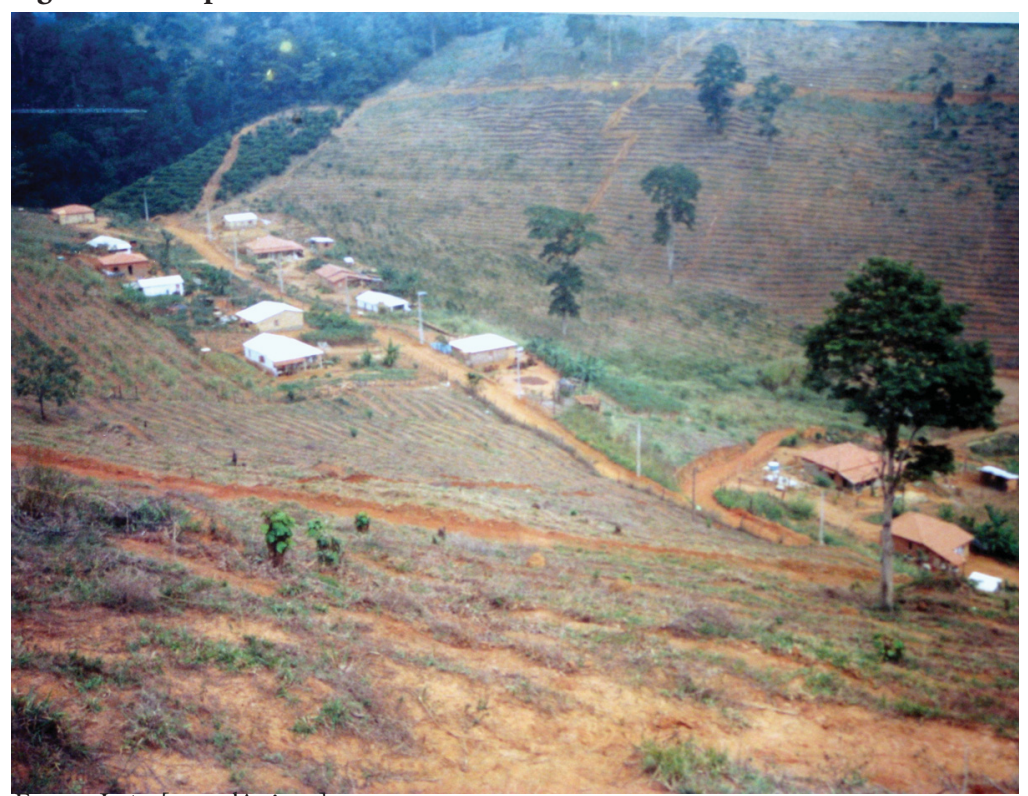

Fonte: Joāo [pseudônimo] e autor. 
Figura 2 - Campos dos Trabalhadores Rurais Sem Terra em 2000 . Trata-se do mesmo local da figura 1, marcado pela árvore à direita, com muito mais vegetaçáo sobre a paisagem

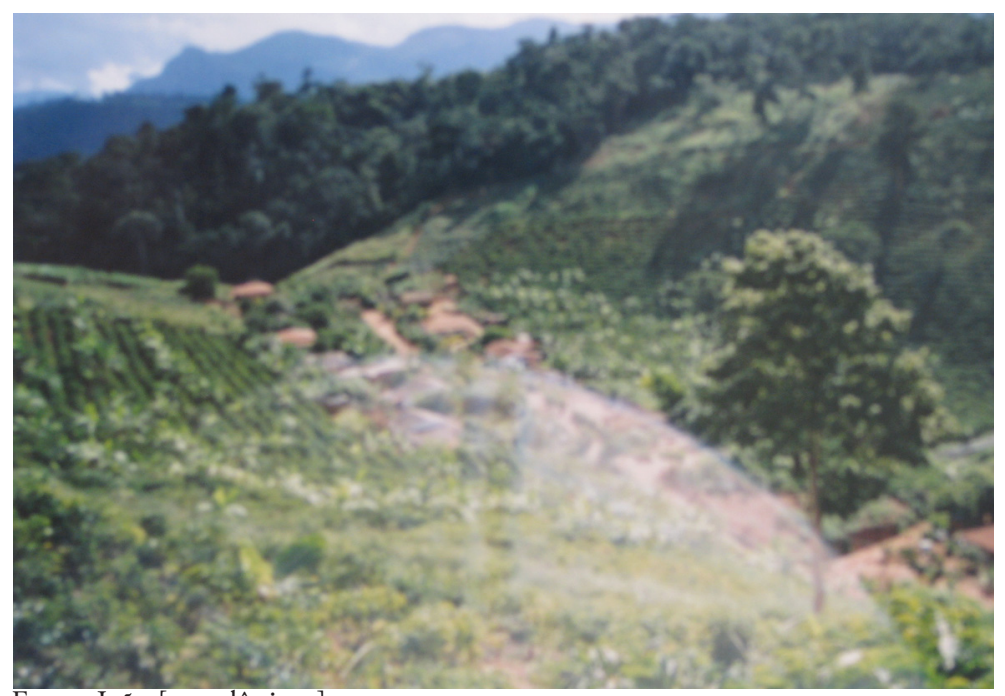

Fonte: João [pseudônimo] e autor.

O que está por trás da declaração "às vezes nós lembramos estes momentos com nossos velhos companheiros e choramos"? O que poderia, no caso de uma pessoa jovem marginalizada, ter sido visto como uma crise de "fracasso" para seguir em frente, torna-se uma vida que constrói a história coletiva a partir de dramáticos momentos de luta, solidariedade e colaboração, partilha de desejos, ideias e produtos, como também de confrontos com a polícia e autoridades legais. João tinha quase vinte anos de idade quando se juntou a um acampamento do MST no Espírito Santo, por volta de 1990, isto é, vinte anos antes de eu conhecê-lo.

Embora João tivesse uma educação básica e possuísse uma pequena propriedade em uma vila vizinha, a maioria das pessoas no acampamento dos Sem Terra pertenciam à parte mais pobre da população brasileira, isto é, pessoas que não tinham nada. Além disso, apresentavam um nível de escolaridade baixo e mal conseguiam ganhar o pão de cada dia. Neste local, muitos tinham experimentado a exploração por parte dos donos de terras que os sobrecarregavam com mais de 12 horas diárias de trabalho forçado nas 
plantaçóes de eucaliptos, ganhando somente o suficiente para comprar um pedaço de pão e, às vezes, uma lata de leite condensado. Outros tinham sido sem teto por semanas em cidades vizinhas, sobrevivendo da coleta de materiais recicláveis das ruas (como papeláo, garrafas plásticas e latas), vendendo-as, novamente, por um pedaço de pão. $\mathrm{O}$ racismo devido à cor da pele e à origem social também foi uma experiência comum para quase todos.

Joâo sempre esteve engajado nas discussóes diárias, participando da coletividade, enfrentando as dificuldades que apareciam. Gostava de viver na companhia dos outros e participava das assembleias que aconteciam todo dia ou duas vezes por semana. Com os outros Sem Terra ele falava sobre o passado coletivo de opressão e da pobreza presente como algo que poderia ter sido diferente se não tivesse existido a exploraçấo. João lentamente tornou-se um dos protagonistas do MST em sua região e entre outras atividades esteve muito engajado em construir a escola local dos Sem Terra, na qual seus dois filhos estudam. Este é um processo intensivo de transformação colaborativa e de sociabilidade no fazer. No contexto do MST, o passado das pessoas marginalizadas foi "renascido", isto é, foi rememorado como o passado colonial e imperialista da apropriaçáo de terras, e, por vezes, o futuro foi visto náo como uma continuação do passado, mas como algo radicalmente diferente - ainda que imprevisível e aberto. Interromper a movimento linear do passado para o presente e futuro e mudar o rumo da história era uma atividade sócio-históricocultural, dramática e que conduzia resultados previamente inimagináveis.

Mesmo que o Movimento dos Trabalhadores Sem Terra tenha aspectos críticos e contradiçóes internas, pode-se afirmar que já alcançou muito mais do que se podia imaginar devido à história capitalista do Brasil colonial e da América Latina em geral (BRANFORD; ROCHA, 2002). Os trabalhadores Sem Terra desencadearam também a organização da Via Campesina na América Latina, em 1992, que se transformou em uma ação entre os quatro continentes em Mons, na Bélgica, já no ano seguinte. A Via Campesina é um movimento transnacional que une milhões de camponeses, pequenos e médios agricultores, Sem Terra, mulheres lavradoras, indígenas, migrantes e agricultores do mundo inteiro. $\mathrm{O}$ movimento representa hoje uma das principais alternativas ao neoliberalismo e consumismo em nível global e defende a agricultura de subsistência em pequena escala como uma forma de promover a justiça social e a dignidade. Ela se opóe fortemente à agricultura corporativa dirigida e às companhias transnacionais que estáo destruindo as pessoas e a natureza. Compreendem atualmente mais 
ou menos 150 organizaçōes locais e nacionais espalhadas por um conjunto de 70 países da África, Ásia, Europa e das Américas, que juntas representam mais de 200 milhóes de trabalhadores do campo.

\section{Olhando para o futuro: pedagogia Sem Terra versus neoliberalismo global}

Num primeiro olhar, a narrativa acima apresentada pode evocar um quase exótico, um espaço ideal que parece distanciar-se do China Central Place em Beijing, do Potsdamer Platz em Berlin, do Rodeo Drive em Beverly Hills, da Avenida Paulista em São Paulo e de muitos outros lugares pelo mundo afora, onde o consumismo neoliberal é proclamado como o principal propósito de vida.

Um olhar mais próximo ao cotidiano dos Trabalhadores Sem Terra revela, entretanto, que eles são parte do mundo contemporâneo e algumas vezes querem consumir mais produtos e mais serviços como todas as outras pessoas, a fim de não se sentirem e não serem percebidos como cidadãos de "segunda categoria". O que pode ser visto como uma exceção, mais ainda como uma versão piorada da tendência consumista dentro do MST, foi que alguns diretores se apropriaram do dinheiro comum para propósitos privados - fato que foi muito criticado pela mídia e levantou fortes polêmicas contra o movimento. Alguns membros do movimento também pegaram dinheiro emprestado dos bancos e não conseguiram pagar, pois em vez de investir a verba na produção agrícola, a utilizaram para construir as suas casas ou comprar motocicletas, por exemplo.

Ensinar e aprender a solidariedade através do projeto "Nossa identidade" apresentado anteriormente, é, de acordo com minha visão, a principal forma como o MST pode superar as tendências consumistas e se desenvolver ainda mais nos próximos anos. Esse projeto político-pedagógico contra o neoliberalismo global não pode ser percebido como um projeto dogmático, acabado ou estável; ele é, por definição, dinâmico e contraditório. A Pedagogia Sem Terra é um movimento claramente difícil, que investe para além das possibilidades dadas, criando novas formas de ser e de tornar-se, escapando das constelaçóes sócioeconômicas e ético-políticas globais.

Qual passado deve ser lembrado? Que futuro deve ser imaginado? Deveriam os Trabalhadores Sem Terra, após ter ganhado um pedaço de terra, 
estabelecerem-se, cultivar suas pequenas propriedades e usufruir de um estilo de vida de classe média, ou deveriam continuar lutando pelo presente e futuro de outras geraçóes de sem terra - incluindo nesta categoria todos os "Outros" que sofrem por causa das relaçôes de poder no Brasil e no mundo inteiro (indígenas, sem tetos urbanos, refugiados de guerras, portadores de HIV que não têm acesso aos medicamentos etc.)?

O nômade, escreve Rosi Braidotti (1994), não deve ser tomado como o sujeito "sem-casa" ou "sem teto" - isto é, em completo desligamento de todas as raízes - nem como alguém em "compulsivo deslocamento" - com seu firme desejo por um lar. Em vez disso, é o "tipo de sujeito que apresenta resignação à toda ideia, desejo ou nostalgia por fixação" (BRAIDOTTI, 1994, p. 22). Tornar-se sem terra, nesse sentido, não é preservar o passado com nostalgia nem mesmo o passado de lutas pelos direitos dos Trabalhadores Rurais Sem Terra; mas é também não tornar-se um consumidor flexível sem qualquer senso de pertencimento.

Tornar-se sem terra implica um movimento sem fim do passado para o futuro e para trás enquanto um constante reescrever da história a partir de "uma comunidade que vem" (AGAMBEN, 1993). Dessa forma, como desenvolver um quadro para ensinar e aprender ciências, línguas e outras matérias através de histórias locais e globais de solidariedade em uma escala cada vez maior? Responder a esta pergunta e continuar a desenvolver o projeto políticopedagógico Sem Terra é o desafio que todos nós enfrentamos agora, depois de 30 anos de construção identitária Sem Terra no Brasil e no mundo.

\section{Notas}

${ }^{1}$ Eu gostaria de agradecer imensamente a tradutora Mari Neiva dos Santos, aos colegas brasileiros Ademir Valdir dos Santos, E. Foerste, G. M. Schutz-Foerste, Berenice Miotto Rodrigues dos Santos e família e todos as outros Trabalhadores Sem Terra anônimos que participaram da minha pesquisa: sem o apoio contínuo, a inspiração e hospitalidade dessas pessoas o presente trabalho não teria sido possível.

${ }^{2}$ Ético-político no sentido da linha de filosofia que conecta Espinoza (2007), Nietzsche (2002), Deleuze e Guattari (1980) e Braidotti (2006), para mencionar somente alguns trabalhos importantes. 
${ }^{3}$ Todos os nomes neste artigo são pseudônimos para proteger as pessoas envolvidas de publicidade não-desejada, por esta razão os nomes dos acampamentos citados em nosso trabalho não são revelados.

${ }^{4}$ Esta análise é acompanhada de um filme curto e de uma apresentação multimídia online (ver LANDLESS..., 2011).

${ }^{5} \mathrm{O}$ MST foi oficialmente fundado durante o primeiro encontro dos Trabalhadores Rurais Sem Terra em Cascavel (PR), em 1984. Para uma visão rápida das informaçóes históricas do movimento e seus primeiros passos antes de 1984, visite o site: http://www.mstbrazil.org/video/ story-mst-part-i. Acesso em: 5 jul. 2013. Para uma revisão da história da colonização e desenvolvimento econômico no Espírito Santo até 1975, veja Gomes (2005). Para conhecer sobre o período entre 1976 e 1996, incluindo detalhes sobre os agronegócios da Aracruz na área principal e dados estatísticos, veja Casali e Pizetta (2005). Pizetta e Souza (2005) também oferecem uma apresentação detalhada da história do MST no Espírito Santo, em diferentes fases: os primeiros passos, de 1983-1985; a constituiçáo do movimento no Espírito Santo, de 19851988; maiores conflitos e repressão, 1989-1991; novas lutas, de 19921994; e estabelecimento e expansão do movimento, de 1995-2002; e o Movimento Sem Terra sob o governo do Presidente Lula, de 2003-2005. O estudo aqui apresentado aconteceu no período entre 2010-2013, e está embasado no que foi apresentado por Pizetta e Souza (2005).

${ }^{6} \mathrm{O}$ Entre outros eventos lembramos o Massacre dos Eldorados dos Carajás, quando 19 trabalhadores foram assassinados e outros 69 feridos pela polícia enquanto estavam bloqueando uma estrada estatal do Pará, no dia 17 de abril de 1996 e a marcha de 13000 trabalhadores Sem Terra de Goiânia à Brasília, em 2005.

\section{REFERÊNCIAS}

AGAMBEN, Giorgio. A comunidade que vem. Tradução de António Guerreiro. Lisboa: Presença, 1993.

APPADURAI, Arjun. Modernity at large: cultural dimensions of globalization. Minneapolis: University of Minnesota Press, 1996. 
BAUMAN, Zygmunt. Consuming life. Cambridge: Polity, 2007.

BRAIDOTTI, Rosi. Nomadic subjects: embodiment and sexual difference in contemporary feminist theory. New York: Columbia University Press, 1994.

BRAIDOTTI, Rosi. Transpositions: on nomadic ethics. Cambridge: Polity, 2006.

BRANFORD, Sue; ROCHA, Jan. Cutting the wire: the story of the Landless Movement in Brazil. London: Latin America Bureau, 2002.

CALDART, Roseli Salete. Pedagogia do Movimento Sem Terra. São Paulo: Expressão Popular, 2004.

CASALI, Derli; PIZETTA, Adelar J. A formação do campesinato e as mudanças recentes na agricultura capixaba. In: SOUZA, Ademilson P. et al. (Org.). A reforma agrária e o MST no Espírito Santo. Vitória, ES: Secretaria Estadual Movimento Sem Terra, 2005. p. 29-72.

DELEUZE, Gilles; GUATTARI, Felix. Mil platôs: capitalismo e esquizofrenia. São Paulo: Editora 34, 1980.

ESPINOZA, Baruch. Ética. Tradução de Tomaz Tadeu) Belo Horizonte: Autêntica, 2007.

FOERSTE, Erineu; FOERSTE-SCHÜTZ, Gerda; DUARTESCHNEIDER, Laura Maria (Org.). Projeto político-pedagógico da educação do campo: por uma educação do campo. Vitória, ES: PRONERA na Região Sudeste, 2008. v. 6.

GOMES, H. Aspectos da história economica do Espírito Santo. In: SOUZA, Ademilson P. et al. (Org.). A reforma agrária e o MST no Espirito Santo. Vitória, ES: Secretaria Estadual Movimento Sem Terra, 2005. p. 15-28.

HARDT, Michael; NEGRI, Antonio. Império. Tradução de Berilo Vargas. Rio de Janeiro: Record, 2001.

KONTOPODIS, M. Neoliberalism, pedagogy and human development: Exploring time, mediation and collectivity in contemporary schools. London \& New York: Routledge/ Taylor \& Francis, 2012. 
KONTOPODIS, M.; MATERA, V. (Org.). Doing memory, doing identity: Politics of the everyday in contemporary global communities. Special Issue of Outlines: Critical Practice Studies, 2010, vol. 2. Disponível em: http:// ojs.statsbiblioteket.dk/index.php/outlines/issue/view/341. Acesso em: 5 jul. 2013.

LANDLESS children/ Sem Terrinha: Espírito Santo, Brazil, 2010. Produção de Michalis Kontopodis. Berlim, 2011. 1 DVD (15 min). Disponível em: $<$ http://landlessmov2010.wordpress.com>. Acesso em: 5 abril. 2014.

LIBERALI, Fernanda Coelho; FUGA, Valdite Pereira. Spinoza and Vygotsky in the production of the concept of reading in the Acting-as-Citizens Project. In: ALANEN, R. PÖYHÖNEN, S. (Org.). Language in action: Vygotskian and Leontievian legacy today. Newcastle, UK: Cambridge Scholars Publishing, 2007, p. 101-124.

MITCHELL, Claudia et al. (Org.). Memory and pedagogy. London: Routledge, 2011.

NIETZSCHE, Friedrich. Assim falava Zaratustra. Tradução de José Mendes de Souza. São Paulo: eBooksBrasil, 2002. Disponível em: <http://www. ebooksbrasil.org/adobeebook/zara.pdf>. Acesso em: 5 jul. 2013.

PIZETTA, Adelar J.; SOUZA, A. P. Entre luta, esperança e utopia: a caminhada do MST no ES no período de 1984 a 2005. In: SOUZA, Ademilson P. et al. (Org.). A reforma agrária e o MST no Espírito Santo. Vitória, ES: Secretaria Estadual Movimento Sem Terra, 2005. p. 73-146.

STEPHENSON, Niamh; PAPADOPOULOS, Dimitris. Analysing everyday experience: social research and political change. London: Palgrave Macmillan, 2006. 
Thirty years of landless identity building in Espírito Santo: exploring a vanguard political-pedagogical project against neoliberalism

\begin{abstract}
The global neoliberalism is marked by a desire to be successful, consume products and services, or even people or intangible property in a non-place, offering an experience of a non-time. Thus, some questions can be asked, for instance: what would be the alternatives to neo-liberalism and what would be the role of pedagogy in this context? Taking as reference the Movement of Landless Workers (MST in Brazil), this paper analyzes how political memory and identity are involved in imagining coming times that do not follow linearly the past. The empirical material comes from an ethnographic research that has been conducted in the last five years (2007-2012) in Espírito Santo State. The article also examines the central components of landless pedagogy, identity construction in school, solidarity and the sharing of memories about the local past as radical alternatives to global neoliberalism. But how can the political-pedagogical project of the Movement of Landless Workers (MST in Brazil) be carried forward to include all "Others" who suffer due to power relations in Brazil and around the globe?
\end{abstract}

\section{Treinta años de construcción de identidad Sin Tierra en el Espírito Santo: explorando un proyecto de vanguardia contra el neoliberalismo}

\section{Resumen}

El neoliberalismo global es marcado por el deseo de tener éxito y consumir los productos, los servicios, incluso las personas o los bienes inmateriales en un aparente "no lugar" ofreciendo una experiencia de un "no-tiempo". Así, algunas preguntas pueden ser realizadas, una de ella es cuáles serían las alternativas para el neoliberalismo y cuál sería el papel da la pedagogía en ese contexto? Teniendo como referencia el Movimiento de los Trabajadores Rurales Sin Tierra (MST) en Brasil el presente texto analiza como las políticas de la memoria y de la identidad están comprometidas en imaginar futuros que no siguen linealmente el pasado. El material empírico que se ha recogido en los últimos cinco años (2007-2012) proviene de una investigación etnográfica realizada en la provincia (Estado) de Espírito Santo. El artículo también analiza los componentes pedagógicos de la pedagogía sin tierra: la construcción de la identidad en la escuela, la solidaridad, el intercambio de recuerdos de los pasados locales y las visiones en desarrollo acerca de los futuros globales ya que han sido los componentes centrales en los últimos 30 años, y constituyen alternativas 
Keywords: Landless Rural Workers realmente radicales al neoliberalismo Movement. Critical Pedagogy. global. Pero ¡cómo puede este proyecto Globalizatio. político-pedagógico de los campesinos sin tierra presentarse como una manera de incluir a todos los "Otros" que está subsumidos a las relaciones de poder en Brasil y en todo el mundo?

Palabras claves: Movimiento de los Trabajadores Rurales Sin Tierra. Pedagogía Crítica. Globalización.

\section{Michalis Kontopodis}

E-mail: michaliskonto@googlemail.com

Recebido em: 29/6/2013

Versăo final recebida em: 5/8/2013

Aprovado em: 10/8/2013 